\title{
LA BASE NAVAL DE CARTAGENA DE LEVANTE DESDE LAS GUERRAS DE SUCESIÓN DE ESPAÑA Y LA CUÁDRUPLE ALIANZA A LA RECUPERACIÓN DE ORÁN (1700-1733)
}

\section{VICENTE MONTOJO MONTOJO \\ REAL ACADEMIA ALFONSO X EL SABIO}

\begin{abstract}
RESUMEN: La base naval de Cartagena, que era el apostadero de las galeras de España desde 1668, se vio muy afectada en la Guerra de Sucesión de España. Las autoridades navales, como el cuatralbo de las galeras y muchos oficiales $-\mathrm{y}$ muchos de los regidores municipales- fueron austracistas y no borbónicos, por lo que en 1706 entregaron la ciudad a las fuerzas navales británicas. El dominio inglés duró menos de seis meses - a diferencia de Alicante, donde fue más largo- pues Cartagena fue recuperada en noviembre de 1706 por tropas borbónicas. Pero tal situación implicó la caída de Orán en manos argelinas, que no fue recuperada hasta 1732. A pesar de ello Cartagena participó en la preparación de las expediciones de Cataluña (1710-1714), Cerdeña y Sicilia (1717-1719) u otras, aunque tales expediciones salieron de Alicante y no de Cartagena. El apostadero naval mantuvo la proveeduría de armadas. En las preparaciones destacaron los comerciantes de la ciudad Julio Antonio Chereguini, Pedro Antonio Pereti y otros genoveses.
\end{abstract}

PALABRAS CLAVE: Historia Militar, Historia Naval, Historia Moderna, Historia de España, Historia Marítima, Siglo XVIII.

\section{THE WAR OF THE SPANISH SUCCESSION (1700-1725) AND THE NAVAL BASE OF CARTAGENA DE LEVANTE}

\begin{abstract}
The naval base of Cartagena, which was the post of galleys in Spain since 1668, was very affected in the War of the Spanish Succession. The naval authorities, like the cuatralbo of the galleys and many officers - and many of the municipal regidores - were Austrian and not Bourbon, so in 1706 they delivered the city to the British naval forces. The English domain lasted less than six months - unlike Alicante, where it was longer - as Cartagena was recovered in November 1706 by Bourbon troops. But such a situation meant the fall of Oran into Algerian hands, which was not recovered until 1732. In spite of it Cartagena participated in the preparation of the expeditions of Catalonia (1710-1714), Sardinia and Sicily (1717-1719) or others, although such expeditions left Alicante and not Cartagena. In these preparations highlighted some merchants in the city, such as Julio Antonio Chereguini, Carlos Rizo and Pedro Antonio Pereti, Genoese.
\end{abstract}

KEYWORDS: Military History, Naval History, Modern History, Spain’s History, Maritime History, Eighteenth Century. 


\section{Introducción}

En este texto se pretende dar a conocer la investigación realizada desde la metodología archivística sobre la provisión naval a la armada española realizada en Cartagena durante el primer tercio del siglo XVIII o en el periodo de las guerras de Sucesión española, de la Cuádruple Alianza y Anglo-española. La metodología archivística consiste en identificar los productores de documentos relacionados con el objeto mencionado, en este caso la proveeduría de armadas y la intendencia de Cartagena.

La armada española quedó muy reducida por razón de la guerra de los Nueve Años con Francia (1689-1697), cuando fueron bombardeadas las ciudades de Alicante, Barcelona y Málaga y fue saqueada Cartagena de Indias por filibusteros franceses, aunque fracasó la expedición escocesa en Darién ${ }^{1}$.

Un ataque inglés a Cádiz en 1702 y 1703 encontró sólo dos barcos (la armada del mar océano, dirigida por el conde de Fernán Núñez) y de cinco a nueve galeras de España ${ }^{2}$, con base en Cartagena de Levante, que defendieron Matagorda ${ }^{3}$. Cartagena fue desde 1668 apostadero marítimo y desde 1529 sede de una proveeduría de las galeras y su actividad generó una documentación que quedó como testimonio de la misma, conservada en diversos archivos, como el naval ${ }^{4}$ y el histórico provincial ${ }^{5}$, lo que permite un conocimiento del devenir desde su propio contexto archivístico.

Al iniciarse la guerra, Portugal se unió a Inglaterra (Tratado de Methuen), Austria y Holanda, como aliados contra España y Francia, por lo que las operaciones se centraron en la frontera de Portugal, lo que dejó indefensas las costas de Levante y Andalucía; los ingleses conquistaron Gibraltar (1704) y al año siguiente llevaron tropas aliadas para conquistar Cataluña y el reino de Valencia, pero también ocuparon Cartagena de Levante (unos meses en 1706) ${ }^{6}$, Alicante (1707-1708), Menorca (1708) y Orán (1708), en que influyó la ocupación

\footnotetext{
1 STORRS, Christopher: 'El 'desastre' del Darien (1698-1700): la pervivencia del poder imperial español en el ocaso de la España de los Habsburgo", Revista de Historia Naval, 18/68, 2000, pp. 7-34.

${ }^{2}$ CASTRO, Concepción de: A la sombra de Felipe $V$ José de Grimaldo, ministro responsable (1703-1726), Madrid, Marcial Pons, 2004, pp. 77-78. PÉREZ-MALLAÍNA BUENO, Pablo Emilio: La política naval en el Atlántico, 1700-1715, Sevilla, Escuela de Estudios Hispanoamericanos, 1982.

3 LÓPEZ GARCÍA, Germán Manuel: "Matagorda: baluarte gaditano", Revista de Historia Naval, 124, 2014, pp. 31-55, cfr. 33-39.

4 VELASCO HERNÁNDEZ, Francisco: "El Archivo Naval de Cartagena: una ventana abierta a la historia del Mediterráneo", Cartagena Histórica, 13, 2005, pp. 30-36.

${ }^{5}$ En el Archivo Histórico Provincial de Murcia se conservan los protocolos o registros de los escribanos de Galeras (Pedro José Villanueva), Marina y Guerra de Cartagena. MONTOJO MONTOJO, Vicente: "El archivo objeto de la archivística: El Archivo Histórico Provincial de Murcia en su 50 aniversario", Murgetana. Revista de la Real Academia Alfonso X el Sabio, 117, 2007, pp. 169-187.

${ }^{6}$ Lord. Just now arrived here at this bay, ... boat from ... ships \& and your letter was given me, dated yesterday
} 
inglesa de Cartagena, pues la escuadra de galeras abrió el puerto a los ingleses ${ }^{7}$, pero la proveeduría de Cartagena dejó de abastecer a Orán. A pesar de ello se dieron unas primeras medidas de reforma de la $\operatorname{armada}^{8}$, pues hubo una primera fase de agresiones navales angloholandesas y otra más larga de recuperación española de Alicante (1708) ${ }^{9}$, Tortosa (1708), Cataluña y Baleares (1711-1715), que dieron lugar a la reorganización de Tinajero en esta última etapa (1714).

La ocupación austracista y anglo-holandesa de Cartagena (1706) y Alicante (17071708) dio lugar a traslados de comerciantes genoveses y franceses de estos puertos a Murcia, ciudad más segura tras el fracaso del ataque austracista de 1706 y la batalla de Almansa (1707), situación que les obligó a continuar sus negocios mediante poderes ${ }^{10}$.

La proveeduría de Cartagena aprovisionó por mar al ejército borbónico de Cataluña, a través de Peñíscola (reino de Valencia), y Tortosa fue zona catalana de recepción de madera de los Pirineos para la construcción y reparación de barcos ${ }^{11}$.

Con Grimaldo colaboró Bernardo Tinajero de la Escalera, quien “conocía bien el funcionamiento del gobierno y del comercio de las Indias. Aunque el tráfico con América estaba supeditado a la defensa de los barcos de guerra franceses, a pesar de ello se quiso recortar los privilegios de los comerciantes de Francia" ${ }^{\prime 2}$.

$\mathrm{y}^{\mathrm{e}}$ of this present with your ... gazettes officials; shave only read those those yt. Are in French, because bunderstand it, and after having stremed your favours, in your believe you intend to put me in Jean only answer yt. Command this place, with orders from ye. King, my Master Philip ye. 5 thr. Whonce God presence, and whit out them shall not attend to any other yr. what is for his Royal service. And as for what your Honourable. Tells me of yours orders which that Noble Genttelman, that is in your company brings to make all your Mischeife he can for your interest, wich you refer to me, ... he dos it on your place of your government, that is at my care, you may ...your self shall procure to event it, till ... my life and in same mind, are all your subjects yt. is in this dominion. God give your Honourable Long live, as you desire. Carthagena, the 29 of August 1706. The Governours name none here can read it, and ... persuive my Leller has not been true by interpreted to him. ... I doubt not but in a little time, he will be made true by sencible ofil. The National Archives, Publics Offices, correspondencia Cartagena, 65.11.

${ }^{7}$ MUÑOZ RODRÍGUEZ, Julio D.: La séptima corona. El Reino de Murcia y la construcción de la lealtad castellana en la Guerra de Sucesión (1680-1725), Murcia, EDITUM, 2014, pp. 152-168.

${ }^{8}$ MARCHENA FERNÁNDEZ, Juan: “De las 'reliquias' de Felipe V a la gran Armada Oceánica de 1750: guerra y marina durante la primera mitad del siglo XVIII", en Estudios de Historia Naval. Actitudes y medios en la Real Armada del s. XVIII, Madrid/Murcia, Ministerio de Defensa, EDITUM, 2012, pp. 49-90, cfr. 62.

9 PRADELLS NADAL, Jesús: Del foralismo al centralismo. Alicante 100-1725, Alicante, Universidad de Alicante, 1984.

${ }^{10}$ De Julio César Manito, genovés residente en Cartagena, a su hermano Juan Bautista Manito, hijos de Juan Domingo Manito y María Teresa Otonello, vecinos de Voltri (Génova), para cobrar deudas debidas a él y a su padre -actuó como testigo Carlos Rizo-; de Luís Dons, mercante francés residente en Cartagena, a D. Pedro Laugier, mercante francés estante en Murcia, para cobrar deuda a D. Diego Fontes, mercader vecino de Murcia, y a Pedro Lombardón, vecino de Alicante, para cobrar 75 libras a José Reig, vecino de Monóvar; de Juan Bautista Basco y Miguel Turón Compañía, franceses de Cartagena, a Laugier para cobrar; y José Esteban del Castillo, bajonista de la parroquia de Cartagena, y $\mathrm{D}^{\mathrm{a}}$ María Are, a herederos de Pedro Pablo Merizano, hombre de negocios difunto, un almacén en el carrerón del Caballero, por 3.600 rls.: Archivo Histórico Provincial de Murcia (AHPM), Not(ariado) 5.774, 11.3, 27.5, 8 y 10.7.1713.

11 Contrato de asiento para maderas de Tortosa: Biblioteca Nacional de Madrid, Sección de Incunables y raros, Papeles curiosos n. 38, Mss. 12.055, fs. 254r-264v, Madrid, 22-2-1715.

12 CASTRO, Concepción de: op.cit., p. 241. Grimaldo fue primero secretario del Despacho de Guerra. 


\section{Imagen 1}

Patente de sanidad de Cartagena con escudo municipal, 1747
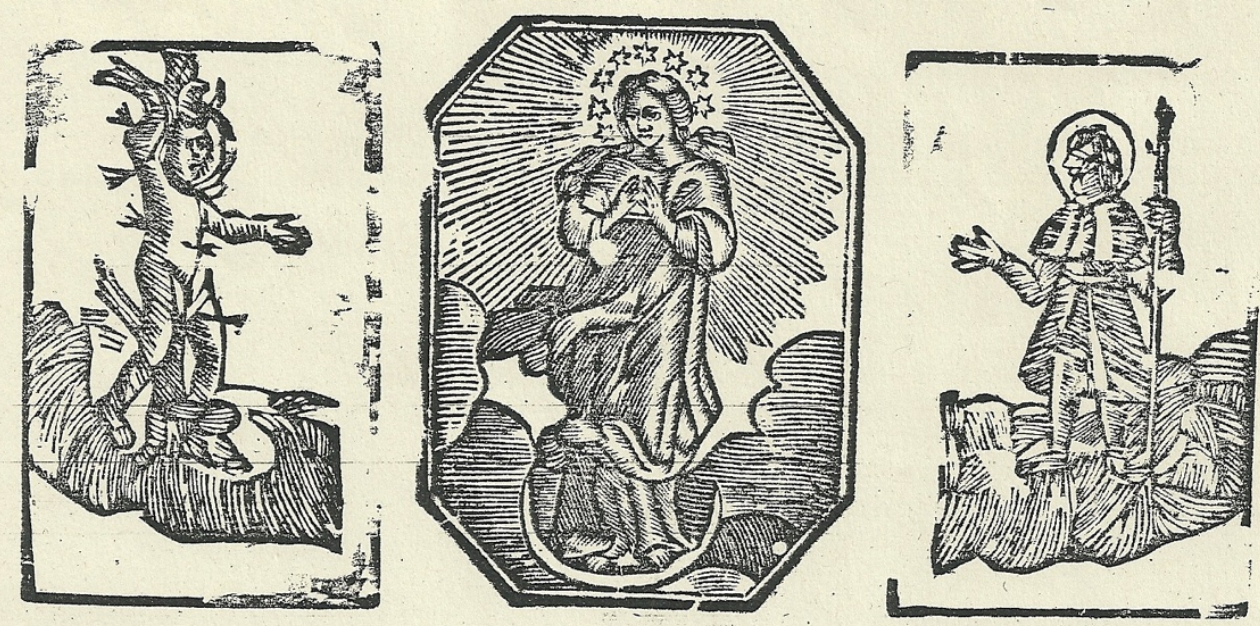

SAN SEBASTIAN.

IA PURISSIMA CONCEPCION.

SAN ROQUE.

EL CONCEJO, JUSTICIA, Y REGIMIENTO DE ESTA MUY NOBLE, y muy Leal Ciudad de Carragena, \&c.

(A Todos, y qualelquier Señores Governadores, Comandantes, Jueces, Jufticias, Cornif2 farios, y Diputados de la faltad publica, y otras qualefquier perfonas à quienes la pre: fentellegáre, y les fuere prefentada, falud, y honor: Los lluftres Señores Corregidor, $y$ Juficia mayor, Ayuntamiento, y Regidores de la ma y Noble, y muy Leal Ciudad de Car-:

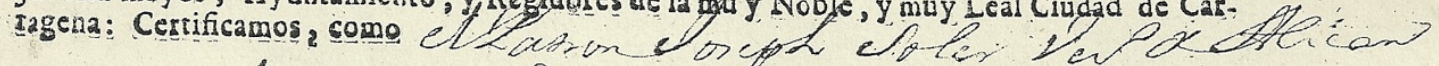

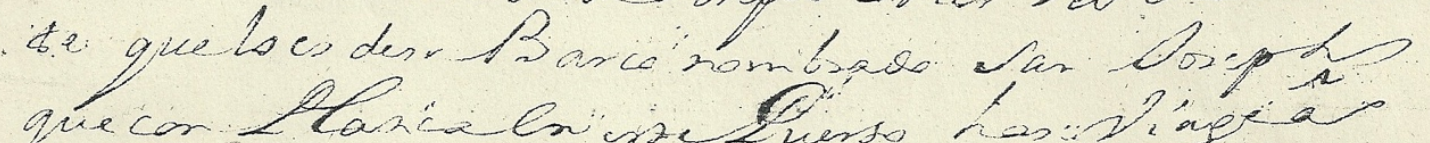

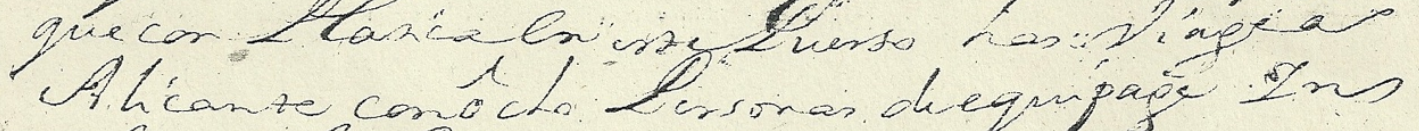
uno gito. Larnow

Torque etta Ciudad, Y fu Jurifdiccion, por la Divina Mifericordia, eftá fana de todo mal contagiofo, y fe guarda de donde efta mandado por Reales ordenes, fe expide la prefente franada de nuefro Efcrivano mayor de Cabildo. En Cartagena, en icako del mes de L. 3 cm bre del año de mil ferecientos quarenta y a reze

Por la M. N. y M. L. Ciudad de Cartagena;
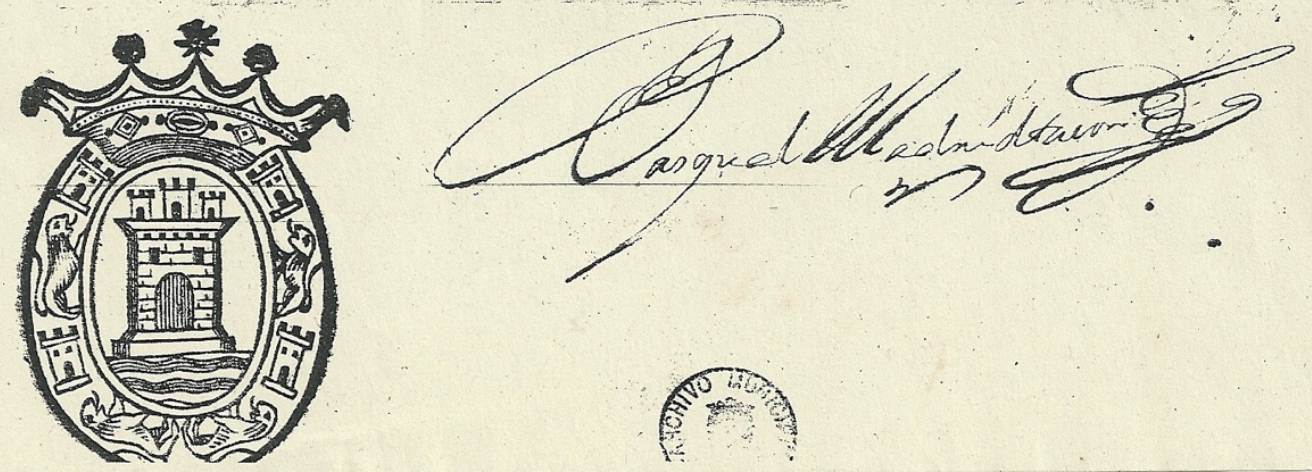

Archivo Municipal de Alicante. Foto Vicente Montojo Montojo. 
Las reformas de Orry y Macanaz fueron en 1713-1714 cambios en las secretarías del despacho y en los consejos. Orry reorganizó la hacienda como veedor general y, al colaborar Grimaldo, ejecutó con eficacia la intendencia del asedio y conquista de Cataluña y Mallorca. José Patiño fue el intendente de la Cataluña, exintendente de Extremadura, y hermano de Baltasar Patiño, marqués de Castelar e intendente general de ejércitos y Aragón ${ }^{13}$, lo que mostró la proliferación de intendentes ${ }^{14}$.

$\mathrm{Al}$ abandonar la armada angloholandesa Cataluña y el Levante español se puso en marcha una escuadra formada por unos pocos navíos comprados, al mando de Andrés de Pez, que aprovisionó al ejército de Cataluña ${ }^{15}$, dirigido por Berwick ${ }^{16}$. En 1715 esta escuadra trasladó al ejército expedicionario que recuperó Mallorca e Ibiza y en 1716 a la expedición de Cefalonia contra Turquía.

\section{E1 revisionismo de los tratados de Utrecht y Rastadt y la armada española}

Los estados contendientes en la Guerra de Sucesión española llegaron a unos acuerdos de paz, los tratados de Utrecht y Rastadt (1713 y 1714), pero fueron efímeros pues Felipe V no aceptó la situación de despojo de territorios a que se le había sometido; en ello tuvo una gran influencia su boda con Isabel de Farnesio, que produjo una revisión continua del reparto de los dominios italianos antes pertenecientes a España: Sicilia, adjudicada a Saboya, y Cerdeña, Milán, Nápoles y los presidios toscanos a Austria.

$\mathrm{El}$ abate Alberoni orquestó la política revisionista, pues organizó la boda de los reyes, dirigió el gobierno, del que salieron los franceses (Orry, Amelot, princesa de Orsini) y Macanaz, y la política de España para recuperar Mallorca, Cerdeña y Sicilia ${ }^{17}$.

Se recuperó Mallorca (1715) con una escuadra formada en Barcelona ${ }^{18}$, compuesta

\footnotetext{
${ }^{13}$ CASTRO, Concepción de: op.cit., pp. 225, 229, 278-281, 329-330.

${ }^{14}$ CRESPO SOLANA, Ana: “La intendencia de marina y el 'gobierno de la contratación': el sueño de José Patiño y Rosales (1717-1736)”, Studia Historica (Historia Moderna), no 39/2 (2017), pp. 75-114. COLL COLL, Ana Ma: "La gestión de la hacienda en un territorio in medio mari: La intendencia de Mallorca en el siglo XVIII", Espacio, Tiempo y Forma (Ha Moderna), 30, 2017, pp. 85-112.

15 ALBAREDA SALVADÓ, Joaquim: La Guerra de Sucesión de España (1700-1714), Barcelona, Crítica, 2012, pp. 360-85.

16 PÉREZ-MALLAÍNA BUENO, Pablo Emilio: "La Marina de guerra española en los comienzos del siglo XVIII (1700-1718)", Revista General de Marina, 199, 1980, pp.137-155. FONT BETANZOS, Francisco: "La deuda de la ciudad de Cádiz con el almirante Andrés de Pez”, Revista de Historia Naval, 121, 2013, pp. 73-92.

17 BAUDOT MONROY, María: "No siempre enemigos. El viaje del Infante don Carlos de Borbón y la expedición naval hispano inglesa a Italia en 1731”, Obradoiro de Historia Moderna, 25, 2016, pp. 243-275.

18 "En lo que a la marina se refiere, Alberoni continuó en la línea iniciada por Orry al final de la última guerra, la de hacer construir algunos barcos y comprar o contratar otros. Era la política deseada por Felipe V, según declaraciones suyas del 23 de agosto de 1715, ya sin el veedor general. Las posibilidades de Orry en 1713-1714 habían sido mínimas, y mínimo igualmente lo que pudo hacer. Como se dijo, se construyeron entonces algunos
} 
de 18 navíos de guerra, 6 galeras, y transportes, con 24 batallones escogidos, 1.200 caballos de desembarco y 600 mulas para la artillería, con muchos pertrechos y municiones. Fue dirigida por Esteban Mari, marqués de Mari, genovés, que aportó tres barcos mediante contrata $^{19}$. El teniente general D’Asfeld mandó el ejército ${ }^{20}$.

La paz del final de la Guerra de Sucesión no permitió la inactividad de la armada, pues en 1717 transportó las tropas que conquistaron Cerdeña, dirigida por Esteban Mari, vicealmirante; Baltasar de Guevara y Francisco Grimau, jefes de escuadras, y Juan Francisco de Bette, marqués de Lede, dirigió las tropas ${ }^{21}$.

José Patiño tuvo un gran protagonismo en preparar la expedición, como intendente general de Marina (desde 1717 y hasta 1726) y presidente de la Casa de Contratación ${ }^{22}$. Unos barcos se fletaron en Alicante ${ }^{23}$ y otros en Cartagena ${ }^{24}$, hasta ahora desconocido, pero desde la Superintendencia de Valencia, pues la proveeduría de armadas de Cartagena quedó supeditada a aquélla cuando se creó la capitanía general de Valencia.

En 1717 puso en marcha la Intendencia General de Marina en Cádiz y el traslado de la Casa de Contratación desde Sevilla a Cádiz ${ }^{25}$. En Cartagena de Levante se pudo dar una

barcos en Vizcaya, Cantabria y La Habana, se reforzaron otros en San Sebastián, comprando al menos uno español y los demás ingleses e italianos. El valido [Alberoni] hizo bastante más: en 1717 se estaban construyendo tres navíos en Pasajes y uno en San Felíu; y en 1718 se habían contratado con tres armadores la construcción de nueve barcos en el mismo Pasajes y en Santander. No puede decirse, sin embargo, que aquello fuera aún la reconstrucción de la armada española; para eso habría que esperar al gobierno de José Patiño y, sobre todo, al del marqués de la Ensenada, con Fernando VI. En cualquier caso, y aunque la mayoría de los navíos y fragatas hubieran sido adquiridos o contratados en otros países con independencia de su calidad, la escuadra enviada a recuperar Sicilia en 1718 se componía de 29 barcos con un total de 1.188 cañones. Aquí se había conseguido fabricar por entonces diez o doce bajeles de 60, 70 y 80 cañones; no estaban destinados todos, sin embargo, a las expediciones mediterráneas, sino también a la escolta de las flotas y galeones, como los de 1713 lo habían estado igualmente al comercio colonial y al sitio de Barcelona": CASTRO, Concepción de: op.cit., p. 344.

${ }^{19}$ CANDÍAN, Guido: "Navi per la nuova marina della Spagna borbónica: l'assiento di Stefano de Mari (17131716)", Mediterranea, ricerche storiche, XII, 2015, pp. 107-146.

20 ARXIU MUNICIPAL DE PALMA: La Guerra de Successió a Mallorca, 1700-1715, Palma, Ajuntament de Palma, 2006. PASCUAL RAMOS, Eduardo: "Formación e instrucciones de la expedición anfibia para la conquista de Mallorca (1715)", Revista Universitaria de Historia Militar, 5, 2016, pp. 46-66.

${ }^{21}$ SALLÉS VILASECA, Nuria: "Que nos odien si también nos temen. El planteamiento estratégico de las campañas de Cerdeña y Sicilia (1717-1718)", Vegueta. Anuario de la Facultad de Geografía e Historia, 16, 2016, pp. 313-334. ALONSO AGUILERA, María Ángeles: La conquista y el dominio español de Cerdeña (1717-1720): introducción a la politica española en el Mediterráneo posterior a la Paz de Utrecht, Valladolid, Universidad de Valladolid, 1977.

22 PÉREZ FERNÁNDEZ-TURÉGANO, Carlos: Patiño y las reformas de la Administración en el reinado de Felipe $V$, Madrid, Ministerio de Defensa, 2009, pp. 89-134.

23 ALBEROLA ROMÀ, Armando: "En torno a la política revisionista de Felipe V: los fletamentos de buques extranjeros en el puerto de Alicante y su empleo en la expedición a Sicilia del año 1718”, Revista de Historia Moderna. Anales de la Universidad de Alicante, 10, 1991, pp. 263-282.

${ }^{24} \mathrm{Al}$ capitán Lorenzo Pereti, francés, de su navío San Miguel Arcángel, de 400 toneladas, y a Simón Bregante francés, del navío Ntra.Sra. de la Guardia, Sta.Catalina y las Almas, de 340 toneladas, por orden de Rodrigo Caballero, superintendente de Valencia, para la expedición a Cerdeña: AHPM, Not. Tauste 5.637/102-3, 1045; 7.7.1717. Tauste inició la serie de escribanos de Guerra, de Cartagena, al servicio del gobierno militar.

25 "Desde el punto de vista administrativo está claro que en estos primeros años de la centuria, la base terminal gaditana se caracteriza por la confusión de competencias entre la Intendencia y la Casa de la Contratación. Esta 
confusión parecida entre la intendencia de marina y la proveeduría de armadas y fronteras, por lo que se suprimió esta última en $1726^{26}$, y entre la intendencia y la aduana, reinstaurada en 1717. La aduana estuvo situada en Murcia hasta entonces y se instauró en 1707 o 1708, con lo que se dio un desquite de Murcia sobre Cartagena, pues Murcia alegó sus méritos de fidelidad borbónica para encasquetarle la aduana a Cartagena, ciudad cuyas autoridades habían sido infieles y se habían pasado al archiduque Carlos de Austria ${ }^{27}$.

La instauración definitiva de la aduana coincidió con el inicio de la Intendencia General de Marina y también se advierte una concomitancia que se dio en Cádiz ${ }^{28}$.

\section{Colaboración de comerciantes de Cartagena en la expedición de Cerdeña}

En la preparación de la expedición de Cerdeña participaron los comerciantes de Cartagena Julio Chereguini y José Chereguini, hermanos genoveses, y Pedro A. Pereti ${ }^{29}$.

Francisco Ibáñez, gobernador de las armas de Cartagena, y Juan de Goyre, oficial mayor de la Comisaría Real de las Galeras, por ausencia de Manuel de Grimau y Peralta, comisario real de ellas, les encargaron 120.000 raciones de marina. Se les pagaron por 5.625 arrobas de vino de buena calidad, con pipas de la misma, 47.812 reales 17 maravedíes, a 8 1⁄2 una; por 268 arrobas de vinagre empipado 1.608 reales, a 6 reales vellón por arroba; por 128 arrobas y 12 libras de aceite empidado 3.471 reales 5 maravedíes vellón a 27 reales; por 128 quintales y 57 libras de bacalao 16.392 reales y 22 maravedíes a 8 1/2 pesos escudos de plata el quintal; por 150 quintales de arroz 9.000 reales vellón a 60 reales quintal, a entregar en los almacenes de Cartagena, previo pago al contado de 77.500 reales vellón, franqueza de derechos y plazo de 40 días $^{30}$.

confusión es casi paralela a la que se sufre en Madrid entre la Secretaría del Despacho y la Gobernación del Consejo de Indias dirigida por Andrés de Pez. Estos dos órganos intentaron aclarar los problemas prácticos que se producían mientras no hubiese otras ordenanzas más claras que unieran oficialmente a las dos materias": CRESPO SOLANA, Ana: La Casa de Contratación y la Intendencia General de la Marina en Cádizz, 1717-1730, Cádiz, Universidad de Cádiz, 1996, p. 157.

26 MONTOJO MONTOJO, Vicente: “De las Atarazanas al Arsenal”, en Julio Mas García (dir.), Historia de Cartagena, tomo VII, Murcia, Ediciones Mediterráneo, 1986, pp. 545-558.

27 MUÑOZ RODRÍGUEZ, Julio D.: La séptima corona. El Reino de Murcia y la construcción de la lealtad castellana en la Guerra de Sucesión (1680-1725), Murcia, EDITUM, 2014, pp. 152-168.

28 "Esta unión de reformas en Marina y comercio es lo realmente innovador de esta política. Ello pudo ser, en gran medida, un motivo más del renacer del tráfico comercial experimentado en el nuevo siglo. En estos primeros años provocó una duplicidad bastante significativa de los dos órganos principales ubicados en el puerto de Cádiz”: CRESPO SOLANA, Ana: op.cit., p. 156.

${ }^{29}$ MONTOJO MONTOJO, Vicente: “El comercio de Alicante y Cartagena tras la Guerra de Sucesión”, Espacio, Tiempo y Forma, serie IV, 23, 2011, pp. 203-226. SEGUÍ ROMÁ, Vicente: Comerciantes extranjeros en Alicante (17001750). Hombres de negocios franceses y genoveses en una ciudad mediterránea, Tesis doctoral, Alicante, Universitat de Alicante, 2012.

30 AHPM, Not. Tauste 5.637, 1713-1717/99-101, 118, 2.7 y 9.1717. 
Los hermanos Chereguini formaron una compañía: Julio Antonio Chereguini, cónsul de Génova en Cartagena, y José Chereguini en Valencia ${ }^{31}$. Julio Chereguini fue negociante y director y proveedor de las tropas de Cartagena, en relación con Urbán Ruiz Velarde, principal asentista general, con quien litigó contra Jaime Nadal Creuz Colomer y Juan Pi, panaderos de Barcelona. Declaró en su testamento ser noble en su ciudad de origen y murió arruinado, había casado en Génova con Antonia Carminati, de una familia vinculada anteriormente al comercio con Cartagena. Andrés Chereguini, su hijo, fue administrador de la renta del tabaco, sucesor de los negocios de Julio Antonio Chereguini y oficial de la contaduría de marina en Cartagena ${ }^{32}$.

Pedro Antonio Pereti fue negociante de Cartagena en 1721-1728 y factor general de las galeras y navíos de España hasta 1743, en que murió, y nombró albacea a Miguel Lavarelo entre otros. Dejó una herencia cuya composición mostró buena posición económica y sensibilidad cultural, así como relaciones con Alicante e Inglaterra ${ }^{33}$.

Hermano de Pedro Antonio fue Lorenzo Pereti ${ }^{34}$, negociante. Hay que resaltar que los negocios entre comerciantes de Alicante y Cartagena fueron entonces muy frecuentes ${ }^{35}$. Muchos de los comerciantes genoveses de Cartagena fueron austracistas en $1706^{36}$,

31 Arrendamiento de un mesón a Antonio Tarrida, francés: AHPM, Not. 5714, f. 53, 2-4-1728.

32 AHPM, Not. Vicente, 6.189/57 y 1, 12.9.1729 y 10.1.1730; 6.191/87, 19.9.1746.

${ }^{33}$ Una heredad de 80 fanegas (su huerta rentó 800 reales anuales), otra de 110 fanegas en La Aljorra, otra de 49 fanegas en Campo Nubla y otra de huerta de 22 tahullas de viña en Las Cañadas o la Torre, que dio 120 arrobas de vino en 1742. La producción la vendía al rey y al pósito. Tuvo además 2.000 cabras y 500 ovejas. José Casal dejó 450 arrobas de vino a 13 reales/1 (5.851), 50 de aguardiente a 16/1 (800), 70 de aceite a 24/1 (1.680), 2 mulas (3.000), una berlina (2.100), una galera (500), platos y tazas de Alcora (200), la loza (1.043'5), una casa en Murcia (5.587), 2 toneles (2.520), un pisador (150), un cuadro de la Purísima Concepción con marco dorado (150), un cuadro de S. Jerónimo (40), un Santo Cristo con marco negro y dorado (30), un cuadrito charolado (30), 8 de figuras (20), una Purísima con marco encarnado (30), 4 cuadros con marco negro (45), 6 de figuras (48), uno de Ntra. Sra. del Rosario (75), un San Cristóbal (45), 4 mapas con marcos dorados (60), una lámina de Ntra. Sra. del Pilar (20), un San José (4), una estampa de los Dolores (4 mrs.), 33 varas de paño encarnado de Murcia apolillado (675), 105 varas de bocasíes negros averiados (550), 75 bultos de bocadillos finos (11.050), 28 bultos de bocadillos ordinarios (4.620), 1.040 varas de lienzo crudo ordinario (2.080), 1.080 varas de creas estrechas (3.510), 13 docenas de filetes de almadraba (993), 24 sarrias para embalar barrilla (18), 200 docenas de lías de esparto (47), una liquidación de débito de Pedro Maurat y consortes (47), y deudas indeterminadas de D. Juan Chavalier, de Alicante, de D. Andrés Celón de Exon, de Inglaterra, D. José Calín, D. José Briñoli y D. Francisco Javier Almela: AHPM, Not. Vicente, 6.189/71, 18.7; 6.180/s.n., 1743.

${ }^{34}$ Manda testamentaria: "Declaro que con don Miguel Ángel Lavarelo, de este comercio, desde el año 1722 tengo una cuenta de diferentes géneros de ropa que le entregué, y quiero que se ajuste y liquide esta cuenta. [...].Que Pereti debía a Lavarelo y Compañía, de Alicante y Cartagena, 970 reales 31 maravedíes": AHPM, Not. Madrid, 5817/495, 1733.

35 Esteban Soler, negociante de Alicante, suegro de Francisco Marbeuf, apoderó a Manuel Soler, su nieto, residente en Cartagena, para cobrar: Archivo Histórico Provincial de Alicante (AHPA), Not. 629/165-166, 166-1727. Entre los acreedores de los herederos de Gaspar Welter y Sulzberger, inglés de Alicante, estuvo José Casal, bearnés de Cartagena (32 libras, 3 sueldos y 2 dineros, 1741). Juan Bautista Fabiani, de Alicante, recibió 100 piezas de calamacos de Alejandro Ríonegro, de Cartagena, 7.12.1728: Archivo Municipal de Alicante, armario 19, caja 72, n. 1. MONTOJO MONTOJO, Vicente: "El comercio de Alicante en el reinado de Carlos II", Saitabi, 60-61, 2010-2011, pp. 327-346.

36 Sobre la rendición de Cartagena a la armada británica: Copy of my setter to the governor of Carthagena

Trocadero, no 31 (2019), ISSN 2445-267X, pp. 175-194 
por lo que se exiliaron fuera de España y sus bienes fueron confiscados y vendidos: Juan Bautista Basco, negociante francés de Cartagena, reclamó una deuda sobre los bienes de Clara Mucio y Antonio Bosomo, exiliados ${ }^{37}$. Fue además el caso de Lorenzo Pereti, pero no de su hermano Pedro Antonio Pereti ${ }^{38}$. Como se deduce del texto de la nota, en efecto, Cartagena era puerto exportador de barrilla.

Lorenzo Pereti, hijo de Marcos Pereti y doña Ana María Pinceti, tuvo cuentas con Manuel Anrich, comerciante cartagenero asociado con ingleses, y José Casal, bearnés, sobre entrega de trigo, y con su hermano Pedro Antonio Pereti sobre entrega de cacao y azúcar, más una letra de 6.000 reales vellón dada por el conde de Abent contra don Pedro Mazón, de Cádiz ${ }^{39}$. Fue yerno de Damián Tomati, comerciante de Cádiz ${ }^{40}$, pues casó con Ángela Tomati. Mantuvo negocios con Damián Tomati e Hijo, de Cádiz, de quienes recibió coloniales como azúcar, cacao, canela y pimienta, que él distribuyó en Cartagena, Murcia y Génova ${ }^{41}$.

dated Aug. 18 1706. Some time since thad a good opportunity of ... your Excellency by since spanyards ... a French ship ... you honour me with a very obliged answer, my busquets then was only to acquaint you of your great Mistres your Queen of Great Britaine \& ... the pence of spaine and to settle your crown in your right line of your ancient House of Austria from to home see many great kings have descended, your ... will please to read, ye. inclosed prints, your find. That God has blessed her Magesties and her alies armes, with great ... asure you, that every part of these papers, is wholly time, I hope your give me credit may thoughts, to believe ... no offert to ... anything, your ... was not soe, soe your we may hope in a very little time to see Spain restored to its antient freedom, trade \& ... I am able to contribute to your benefit or happiness in these parts, I shall be ready upon your last notice given at any time to Jamaica you are assured of your Governour of that place rending at all times to dure your same. The Nobly gentlemen that is now with ... home her Majesties of Great Britain has sent out with a good squadron of men of war, will porpoise all opportunitys of docing your greates services he can for the interest of his Catholic Majesty Charles II (3d) whone God presence. May your life belong $\&$ as happy as you desire is the hartey wishes of your Chancellency. Most humble servant. TNA, Londres, $\mathrm{PO}$, correspondencia Cartagena, $65 \mathrm{i}$.

${ }^{37}$ AHPM, Not. Vicente, 6.189/5-6, 30.7.1722.

${ }^{38}$ Lorenzo declaró: "Digo que por cuanto en el año 1706 al querer entrar las armas de S.M. en esta plaza, salí de ella de orden de doña Ana María Pinceti, mi madre, con unas arcas con diferentes alhajas, 35 sarrias de barrilla, un cajón de añil y 305 1/2 pesos en dinero, que habiéndome embarcado con dichos efectos en un navío y llegado a Barcelona, tuve orden de don Pedro Antonio Pereti, mi hermano, para que restituyese dichas arcas, lo que ejecuté y llegaron a salvamento a poder de mi madre, y habiéndome quedado con dichos efectos y dinero, por el año 1716 o 1717 que vine a esta ciudad dí cuenta de ellos": AHPM, Not. Madrid, 5.817/495, 1733.

39 "Declaro que de las cuentas del tiempo que estuve en Génova y tuve con don Pedro Antonio Pereti, mi hermano, de géneros y efectos que me remitió a ella para su beneficio, no tengo a cargo cantidad alguna del susodicho, antes bien, en la partida que aboné cobrada en Cerdeña y en la partida de los fletes de la balandra, que cobré de Genis y Puigserver, se hallará haber abonado más de lo cobrado, y menos haber negociado con estos caudales cosa alguna, en que me puedo haber habilitado, como se presume, pues aunque en dicha Génova hice algunos negocios de cuenta y mitad con don Manuel Anrich, por lo que tocaba a mi mitad le sacaba sobre mismos efectos letra de cambio, y aunque hubo algún beneficio, al último se perdió por la toma del navío del capitán Delfín, ni que remitía algunos efectos de cuenta y mitad con el dicho don Manuel Anrich. Declaro no tener cobradas de cuenta de don Pedro Antonio Pereti, mi hermano, efectos ni cantidad alguna, ni menos del navío que mandaba el capitán Mitre. Y respecto que sobre el mismo navío de Mitre, que ya lo mandaba el capitán Carcaño, en que tenía la mitad mi hermano, desde el susodicho si en los seguros que me dio orden hacer sobre él aseguré más 1.000 pesos de los que le dicté. Declaro sobre mi conciencia que no fueron más los seguros que 2.000 pesos" (Ídem).

${ }^{40}$ BUSTOS RODRÍGUEZ, Manuel: Cádiz en el sistema atlántico, Cádiz, Sílex Ediciones, 2005, p. 98.

41 'Y además de esto, como consta de mi libro, deberá dar cuenta de 7.600 pesos que por las escrituras que se 
Hubo otros productos procedentes de Hermanos Mazones de Cádiz (5.225 fanegas de trigo). Con él participó Pedro Vergez, francés, escriturario de Carlos María Rizo (con 1/3 de 6 balas de pimienta y 2 churros de canela); Mateo Solicofre, vecino de Cartagena de origen francés y suizo, o José Casal, mercader francés de Cartagena ${ }^{42}$. Aparecieron así comerciantes bearneses franceses, al principio subordinados a los genoveses.

A través de su suegro envió ropa o textiles a Indias, que dispuso que declarara aquél y a través de su cuñado Lorenzo Tomati negoció 7.600 pesos con Andrés de Beas, vecino del Puerto de Santa María, a pagar en Cartagena de Indias, de cuya cantidad perteneció la cuarta parte a Lorenzo Pereti y el resto a diferentes mercaderes de Génova. Entre estos estuvieron los Frugoni, a quienes llevó de Lisboa 200 cajas de azúcar en su navío, que allí compró de su cuenta.

En definitiva la actividad mercantil de Lorenzo Pereti, testimoniada por su inventario y partición de bienes, revela a un exportador de barrilla o sosa de Cartagena, Alicante y Murcia, y un importador de coloniales como azúcar (La Habana) y cacao (Caracas y Guayaquil $^{43}$, y bien relacionado con el comercio de Cádiz por lazos familiares, cosa muy normal en Cartagena y Alicante.

Lorenzo Pereti puede ser comparado a los genoveses Panés de Cádiz (Juan Lorenzo y Leandro Panés) y Cartagena (Juan Andrés, Agustín Panés, que habían fallecido no mucho tiempo antes, y otros: Pedro Francisco Panesi), quienes mantuvieron negocios en Cádiz con Indias o América española.

Para paliar los efectos negativos de la pérdida de las flotas mercantes se desarrolló enormemente en Cádiz el sistema de riesgos marítimos en sus distintas modalidades: de permiso, de apuesta, de vida, de prorrateo y de pignoración ${ }^{44}$. La actividad financiera sobre

hicieron a favor de don Lorenzo Tomati, mi hermano, me quedó debiendo don Andrés de Beas, vecino del Puerto de Santa María, a pagar en Cartagena de Indias, cuya cantidad pertenece la cuarta parte a mí y el resto a diferentes mercaderes de Génova. Declaro que la casa de los Señores Frugones, de Génova, habiéndoles llevado de Lisboa 200 cajas de azúcar en mi navío, que allí compré de su cuenta, y entregádoles la carta cuenta, y después de haber quebrado la casa de dichos Frugones, parece me escribieron haber error en dicha cuenta de 1.400 libras de aquella moneda, y en caso de ser así cierto, y que ocurran los acreedores a dicha casa de Frugoni, se les satisfagan por mis herederos" (Ibidem nota 40).

42 "Declaro que Pedro Vergez, escriturario de don Carlos María Rizo, tiene interés en la tercera parte de 6 balas de pimienta y 2 churros de canela. Declaro que Mateo Solicofre, vecino, tiene que dar cuenta de tres cargos de trigo que recibió de mi orden y de ellos es deudor de 13 a 14.000 r., y además de esto, tiene hoy a su cargo 5.160 fanegas de trigo de que deberá dar cuenta, cuya porción de trigo pertenece a los Hermanos Mazones de Cádiz. Declaro que con don Miguel Ángel Lavarelo, de este comercio, desde el año 1722 tengo una cuenta de diferentes géneros de ropa que le entregué, y quiero que se ajuste y liquide esta cuenta" (Ibidem).

43 "Que Jerónimo y Juan Bautista Fabián, de Alicante, deben a Pereti 781 reales 8 maravedíes. [...] Que Pereti debía a Lavarelo y Compañía, de Alicante y Cartagena, 970 reales 31 maravedíes". "Declaro que en mi libro se hallarán unas cuentas de diferentes géneros que tengo remitidos a don Juan Antonio Collado, vecino de la ciudad de Murcia, a quien se pida cuenta de ello" (Ibidem). SZASZDI NAGY, Adam: "El comercio hasta la implantación del comercio libre", en Historia General de España y América, t. XI/2, Madrid, Rialp, 2a ed., 1992, pp. 277-324.

44 RAVINA MARTÍN, Manuel, "Riesgos marítimos en la Carrera de Indias", Documentación y archivos de la colonización española, Madrid, Ministerio de Cultura, 1980, II, pp. 103-157, cfr. 137-138. 
riesgos marítimos surgió del aumento de la inseguridad marítima y tuvo como telón de fondo el emplazamiento del monopolio de Indias.

Se recibían letras de cambio de Cádiz en Alicante, como lo hizo el genovés Jerónimo Pinton del capitán Guillermo Maya, también genovés, que le libró 2 cédulas, una de 55 doblones sobre Agustín María Pedecina, vecino de Cádiz, sobre Domingo $\mathrm{M}^{a}$ Viseti, genovés $(1700)^{45}$; o se establecieron también compañías, como la de Luca $\mathrm{M}^{\mathrm{a}}$ Teatos, negociante genovés en Alicante, con Vicencio Nervi, negociante de Cádiz, a quien hubo de tomar cuentas el primero en escala hacia Londres ${ }^{46}$, y hubo unas redes mercantiles Cádiz-Cartagena, pues Juan Andrea Panés comerciante y vecino de Cartagena y Murcia, trabajó unos años en Cádiz $^{47}$, junto a su hermano Fulgencio Panés y su tío Juan Lorenzo, como se puede comprobar en esta tabla, con fechas no muy lejanas ${ }^{48}$ :

\begin{tabular}{|l|l|l|l|l|}
\hline Actos notariales & Otorgante & Destinatario & Fecha & Signatura \\
\hline Poder para testar & Fulgencio Panés & Juan Andrea Panés & $4-11-1662$ & $3069 / 1855$ \\
\hline Testamento & Fulgencio Panés & & $16-6-1681$ & $3092 / 571$ \\
\hline Poder para testar & Fulgencio Panés & Diego Ag. de Rojas & $1-4-1687$ & $3100 / 252$ \\
\hline Testamento pod. & Fulgencio Panés & & $14-3-1691$ & $3104 / 176$ \\
\hline Poder & Luis Panés Figueroa & Juan Lorenzo Panés & $13-4-1689$ & $5464 / 47$ \\
\hline Obligación riesgo & Fulgencio Panés & Pedro Toscano & $10-1-1687$ & $3100 / 19$ \\
\hline Protesto & Fulgencio Panés & Felipe Arroyo & $16-1-1687$ & $3100 / 41$ \\
\hline Poder & Fulgencio Panés & Bernardo Sánchez & $1-2-1687$ & $3100 / 84$ \\
\hline Protesto & Fulgencio Panés & Antonio Morales & $28-2-1687$ & $3100 / 143$ \\
\hline Poder & Fulgencio Panés & Baltasar Catáneo & $3-3-1687$ & $3100 / 158$ \\
\hline Protesto & Fulgencio Panés & Juan Ernesto Troya & $5-3-1687$ & $3100 / 165$ \\
\hline Protesto & Fulgencio Panés & Antonio Morales & $5-3-1687$ & $3100 / 166$ \\
\hline Protesto & Fulgencio Panés & Antonio Morales & $5-3-1687$ & $3100 / 168$ \\
\hline
\end{tabular}

Fuente: Archivo Histórico Provincial de Cádiz: Protocolos notariales.

\footnotetext{
45 Archivo Histórico de Orihuela (AHO), Not. Verdiel 1.212/273r-281r, 25-9-1695. En este archivo se conservan los protocolos de este notario de Alicante (anteriores a los del AHPA), que fue borbónico, por lo que hubo de exiliarse durante el dominio austracista, a lo que se debe esta situación de sus registros.

46 De su compañía tenía 76 docenas de guantes ordinarios de Génova, 8 carpazos de pluma bordados de oro y plata y 2 cajas de jaboncillos de afeitar (60 a 70 docenas). Nervi hubo de pagar 20 escudos: AHO, Not. Verdiel 1.216/95v, 1.5.1700.

47 Declaró en su testamento: «por cuanto al Señor Don Juan Lorenzo Panés, mi tío, vecino que fue de la ciudad de Cádiz, yo y el dicho Sr. D. Fulgencio Panés, mi hermano y mi heredero que ha de ser, debimos muy especiales honras y asistencias de que nos hallamos deudores y con obligación de remunerarlo y a mi parecer la mejor demostración será hacer alguna fundación de obra pía perpetua por el alma de dicho Sr. D. Juan Lorenzo Panés y por el de dicho Sr. mi hermano y más y como gustare el susodicho, pues en ello Dios nuestro señor será reverenciado»: AHPM, Not. Peinado 1.821/27-49, 9.2.1686.

48 BUSTOS RODRÍGUEZ, Manuel: "Los siglos decisivos", en Historia de Cádiz, Madrid, Silex ediciones, 2005, pp. 283-398. Ídem. "La burguesía mercantil en el Cádiz del siglo XVII: proceso de formación y estructura", en Congreso Internacional La Burguesía española en el Antiguo Régimen (Madrid, 1991), Valladolid, Universidad de Valladolid, 1996, pp. 1233-1265.
} 


\begin{tabular}{|l|l|l|l|}
\hline Acrredores de Juan Andrea Panés & & & cantidad \\
\hline Viuda de Simón Giménez & mercader & Murcia & $200-300$ reales \\
\hline Belando, Juan Lorenzo & mercader & Murcia & \\
\hline Piani, Jorge & mercader & Murcia & \\
\hline Tuero, Francisco & cerero & Murcia & \\
\hline Montanaro, Juan Bta. & negociante & Cartagena & 4 arrobas de hierro \\
\hline Monranaro, Juan Bta. & negociante & Cartagena & 24 reales \\
\hline Polero, Francisco & negociante & Cartagena & 2 arrobas bacalao \\
\hline Bartoloto, Andrés & negociante & Cartagena & 81 reales diezmo barrilla \\
\hline Molera, Juan & mercader & Cartagena & 12 reales por Po Arecio \\
\hline Bartoloto, Andrés & negociante & Cartagena & 3 arrobas de barrilla \\
\hline Lomelín, Pablo & negociante & Alicante & 30 doblones de a 2 \\
\hline Truyol, Martín & mercader & Murcia & \\
\hline Vigo, Juan Jerónimo & mercader & Murcia & 120 reales \\
\hline Montemayor, Pedro & capitán & Cartagena & \\
\hline Fábrega, Domingo & regidor & Cartagena & \\
\hline Esquarzafigo, Carlos & & Murcia & Porte 116 arrobas arroz \\
\hline Porcelo, Francisco $\mathrm{M}^{\mathrm{a}}$ & & Madrid & 391 reales \\
\hline
\end{tabular}

Es decir, hubo una cierta relación entre Cartagena de Levante o Alicante y Cádiz ${ }^{49}$, que se comprende mejor si tenemos en cuenta que desde Lisboa Juan Martín Piquer y compañía (1696-1698) enviaron sobre todo azúcar y tabaco de Brasil a Cádiz y los puertos españoles del Mediterráneo: desde Málaga a Barcelona, por medio de barcos de catalanes y mallorquines. Tanto Barcelona (Tomás Briñoni: 308 cajas de azúcar blanco de Paraiba, Pernambuco y Río, 100 rollos de tabaco; José March y compañía: felpas y libros; Juan Catá: 1 caja de azúcar blanco de Bahía y 2 sacos de tabaco de Brasil; José Rodoreda: 2 rollos de tabaco de Brasil), Salou (Isidoro Rabaza, de Selva: 6 rollos de tabaco de Brasil y 10 cajas de azúcar blanco de Bahía), Valencia (Juan Escrig: 28 cajas de azúcar blanco de Pernambuco, 50 rollos de tabaco de Brasil, 120 pipas de vino; y Juan de Superviela: 60 cajas de azúcar blanco de Baía y Paraiba), Denia (Jaime Verdeguer: 82 cajas de azúcar blanco de Bahía y Pernambuco, 30 rollos de tabaco de Brasil, 13 balones de papel, 22 sacos de arroz, 13 pipas de aguardiente; y Tomás Verdeguer: 13 sacos de arroz, Felipe Vives), Alicante (Feterstone y Ayles: 12 cajas de azúcar blanco de Brasil y 30 rollos de tabaco), Cartagena (Esteban Lamberto Maldonado: 16 cajas y 33 sacos de azúcar blanco de Pernambuco y 20 rollos de tabaco), Málaga (Francisco Neuland: 27 cajas de azúcar blanco de Bahía y 31 rollos de tabaco de Brasil) y Cádiz, (Pedro Dalmau: 50 cajas de avellanas, 74 cajas de azúcar blanco de Bahía y Paraiba y 30 rollos de tabaco, Iusepe Rabaza : 6 cajas de azúcar blanco de Paraiba).

49 Tomás Jefreys pagó 14.400 reales a Juan Gadamer y cía de Cádiz de orden de Joan Amengual Gil, de Mallorca, en 25.9.1683: BIBILONI AMENGUAL, Antoni: El comerc exterior de Mallorca. Homes, mercats i productes d'intercanvi (1650-1720), Palma de Mallorca, El Tall Editorial, 1995, p. 47, notas 122-123. 
Envió tabaco de Brasil y azúcar blanco de Bahía con patrones de barcos, que recibieron a cambio algunas cantidades de aguardiente, arroz, avellanas, papel y vino, y cobraron una comisión de $1 / 4 \%$ de limosna para la imagen de la Virgen de Monserrat, además del corretaje y otros conceptos ${ }^{50}$. Este tipo de situación lo vivieron también los Merizano ${ }^{51}$. Por otra parte, desde Alicante y Cartagena de Levante tanto comerciantes bretones como genoveses, muy asentados en estos puertos ${ }^{52}$, extendieron sus redes laborales y familiares a Sevilla y Cádiz, como en los casos de los Tacón ${ }^{53}$ y Panés o Panesi. La instalación de bretones malouinos continuó en el caso de Marbeuf, aunque se hizo cada vez menor con respecto a bearneses y marselleses, como el cónsul Magín Iznardo ${ }^{54}$.

\section{El intendente Rubalcava y la época de Patiño (1726-1736) en el departamento naval}

Esta etapa de José Patiño como secretario de Marina e Indias (1726-1736) coincidió con el inicio del departamento marítimo, a la vuelta de Felipe V como rey tras la muerte de su hijo Luís I (1724) y el regreso de Grimaldo al ministerio o primera secretaría del despacho de Estado ${ }^{55}$. Patiño creó en 1726, como secretario del Despacho de Marina e Indias, los departamentos marítimos de Cartagena, Ferrol y La Habana, reorganizó los arsenales y aumentó la construcción de navíos en astilleros españoles ${ }^{56}$. Estas medidas, junto con la

\footnotetext{
50 Copiador de facturas de Martín y Riquer: Biblioteca Universitaria de Barcelona, Manuscrito 959. Ver: MARTÍNEZ SHAW, Carlos: "Algunos aspectos del comercio valenciano con Lisboa a fines del siglo XVII", en Primer Congreso de Historia del País Valenciano, vol. 3, Valencia, 1976, pp. 473-490.

51 Pedro Pablo Merizano, veneciano, fue cónsul de Malta hasta 1707. En 1730-1740 otro Pedro Merizano estuvo asociado a Benzi en Barcelona y tramitó letras de pago entre Ramón de Falguera Brocá, administrador del marqués de Santa Cruz en Cataluña, y éste, con intervención de Benages, Andreu y Milans o Dalmases, Catá y Piria de Barcelona, y Rodulfo Firidolfi, Carlos Maracci, D. Pedro Astrearena, Patricio Joyes y los Bretous de Madrid: Archivo Histórico Nobleza, Frías+, c a 310/1, años 1725-1741. MAIXÉ ALTÉS, J. Carles: "Aproximación a la colonia genovesa, un sector de la burguesía barcelonesa en el siglo XVII: la familia Bensi", Comercio y banca en la Cataluña del siglo XV III. La Compañia Bensi \& Merizano de Barcelona (1724-1750), A Coruña, Universidade da Coruña, 1993.

52 MONTOJO MONTOJO, Vicente/RUIZ IBÁÑEZ, José Javier: "Le comunità mercantili di Genova e Saint Malo a Cartagine, porta della Castiglia”, en G. MOTTA ed., Mercanti e viaggiatori per le vie del mondo, Milán, Franco Angeli, 2000, pp. 75-90.

53 Pedro Fernández de la Torre, proveedor de armadas y fronteras de Cartagena, apoderó a Juan Sánchez de Oyanguren, contador de las galeras de España, vecino de Puerto de Santa María, para cobrar a Juan Agustín Tacón Briñoli, vecino de Sevilla, hermano de Juan Carlos Tacón Briñoli, regidor y vecino de Cartagena, 1.502 pesos de plata doble que cobró a Pedro y Juan de Soto López, de Sevilla, por poder: AHPM, Not. Torres $5.460 / 665,1662$.

${ }^{54}$ Iznardo, como otros muchos, se dedicó a exportar barrilla y sosa, por lo que apoderó a Pedro Germán, francés residente en Alicante, para cobrar a Roque Beltrán, francés de Martega, patrón de una saetía, 380 reales por 600 quintales de barrilla a embarcar: AHPM, Not. Torres 5.460/350, 1662.

55 CASTRO MONSALVE, Concepción de: "El Estado español en el siglo XVIII. Su configuración durante los primeros años del reinado de Felipe V”, Historia y politica, 4, 2000, pp. 137-170.

56 MERINO NAVARRO, José Patricio: La Armada española en el siglo XVIII, Madrid, Ministerio de Defensa, 1981, pp. 18, 22-4. DE LA PIÑERA Y RIVAS, Álvaro/RUBIO PAREDES, José Má: Los ingenieros militares en la construcción de la base naval de Cartagena (siglo XVIII), Madrid, Ministerio del Ejército, 1988, p. 59.
} 
presión de los corsarios españoles, permitieron la defensa de los territorios españoles y de las colonias americanas en los años 1726-1729 frente a las agresiones británicas (Guerra Anglo-española), aunque según algunos autores la armada estuvo carente de buenas tripulaciones y muchos barcos se perdieron por ello ${ }^{57}$.

El Departamento marítimo de Levante, o de Cartagena se puso en marcha en 1728. Su institución dio lugar a la aplicación de la organización que tuvo el Departamento de Cádiz: es decir, el nombramiento de un comandante general (luego capitán general) y el de un intendente del departamento ${ }^{58}$. El comandante general fue la máxima autoridad, pero con frecuencia se ausentó para participar en expediciones navales, por lo que el intendente tuvo más relieve. Estos nombramientos dieron lugar al archivo naval.

El intendente dirigió sus oficinas: la secretaría, la contaduría, el arsenal y las matrículas de mar, lo que derivó de la organización que dio Patiño al Cuerpo de Ministerio, formado por intendentes a la cabeza, comisarios ordenadores, comisarios de guerra y de provincia, oficiales primeros y segundos, contadores de navío, de fragata y oficiales supernumerarios ${ }^{59}$. Hasta 1736 las oficinas de Cartagena estuvieron dirigidas por un comisario ordenador, no por un intendente ${ }^{60}$. Fueron comisarios principales Alonso de Varas durante un breve tiempo, y Alejo Gutiérrez de Rubalcava, quien coordinó la organización del departamento. La recepción de órdenes formó la serie Reales órdenes.

Primero se tomó las medidas de designar el paraje donde estarían las galeras ${ }^{61}$ y navíos, confiada al ingeniero Juan de la Ferriere ${ }^{62}$, y dragar el puerto. Además se aprestaron materiales para las expediciones navales a Italia, que necesitaron de caudales y suministros pagados por las tesorerías de Guerra y Marina con las rentas generales (de aduanas e Indias), no las provinciales (alcabalas y servicios de millones), y sí algunas estancadas (la renta del tabaco) y eclesiásticas (Cruzada, subsidio y excusado, contabilizadas por la Tesorería de la Cruzada).

\footnotetext{
${ }^{57}$ MARCHENA FERNÁNDEZ, Juan: op.cit., p. 87.

${ }^{58}$ Con una carta a Juan Ferriere: PÉREZ FERNÁNDEZ-TURÉGANO, Carlos: "La Secretaría del despacho de Marina y la fundación del Arsenal de Cartagena (1728-1736)", Murgetana. Revista de la Real Academia Alfonso Xel Sabio, 97, 1998, pp. 63-72.

${ }^{59}$ MERINO NAVARRO, José Patricio: op.cit., p. 42.

${ }^{60}$ pero como a tal le correspondía: "[...] el mando general y absoluto en todo lo administrativo y gubernativo de aquellos importantes establecimientos (arsenales). La dirección de las faenas marineras del arsenal, los trabajos de la maestranza, la inspección de los pertrechos, su exclusión y reemplazo, etc.; corrían a cargo del jefe del ramo facultativo, denominado Capitán de maestranza, y los acopios de materiales, la custodia y buena colocación de los efectos, la contabilidad de haberes, y todos los demás asuntos económicos, se hallaban a cargo del Ministerio de Real Hacienda; gobernándose ambos funcionarios por las providencias del Intendente que, como hemos dicho, reunía la autoridad general y exclusiva": MERINO NAVARRO, José Patricio: op.cit., p. 43. ${ }^{61}$ FONDEVILA SILVA, Pedro: "Las galeras de España del siglo XVIII”, Revista General de Marina, agosto-sept. (2004), pp. 223-237.

${ }^{62}$ DE LA PIÑERA RIVAS, Álvaro/RUBIO PAREDES, José María: op.cit., p. 61.
} 
Financieros navarros obtuvieron los asientos de suministros ${ }^{63}$, como Iturralde, Aldaz, Loperena, Arizcun y otros a partir del arrendamiento de rentas provinciales ${ }^{64}$, lo que marcó un cambio: el final del predominio de los genoveses en los asientos grandes, pero no en otros como el de Lavarelo.

Fue necesario un esfuerzo de coordinación entre las diferentes tesorerías y la intendencia de Marina, que incluía a los oficiales llamados ministros de Marina de Baleares (Bernabé de Ortega), Cataluña y reinos de Valencia y Murcia.

Mientras fue intendente Alejo Gutiérrez de Rubalcaba (1731-1742) desde Madrid se adjudicaron como ingresos a la tesorería del departamento, que dependió del intendente, el subsidio y excusado eclesiásticos de Tarragona, el derecho de ancoraje del puerto de Cartagena (1731) y de los puertos catalanes y valencianos, caudales de la aduana de Alicante, dirigida por el navarro Juan Bautista Iturralde ${ }^{65}$, que se necesitaron para finalizar las obras de los 6 almacenes y el malecón, sueldos de empleados, fábrica de pontones y limpia del puerto. Entre estos gastos los sueldos del personal eran fijos. Los derechos de puertos marítimos incluían los de ancoraje, toneladas, limpia y linterna, que eran administrados por la marina.

Los gastos del departamento fueron cubiertos con caudales de Indias, remitidos desde Cádiz (6.000 pesos), o de la renta del tabaco de Murcia: como 4.000 doblones para obras del puerto, parte de 30.000 reales mensuales que se destinaban y que en 1733 se retrasaron por causa de los directores de la renta, entre ellos el marqués de Perales.

Se sumaron 40.000 reales mensuales de la aduana de Cartagena y 75.000 de la de Alicante. Cantidades mayores (56.000 y 84.000 reales) se enviaron desde las tesorerías de Cruzada de Cataluña y de Valencia, ciudad de la que se remitió dinero de la renta del tabaco. Algunos de los problemas que surgieron al instaurar el derecho de ancoraje y toneladas fueron que en Palamós ya existía tal derecho, a favor del duque de César, con el que hubo

\footnotetext{
${ }^{63}$ GONZÁLEZ ENCISO, Agustín: “Empresarios navarros en la industria de armamento del Estado. La fábrica de Eugui”, en Rafael Torres Sánchez (ed.), Volver a la hora navarra, Pamplona, EUNSA, 2010, pp. 159-211.

64 "Los navarros entraron en este negocio en la mejor coyuntura posible. Por un lado el ascenso de Goyeneche y la Guerra de Sucesión y por otro Patiño y el avance de una política contratista nacional parece estar en la base de esta entrada en el negocio de las provisiones de víveres a la Armada. El primer factor se sitúa en el tránsito al siglo XVIII, cuando Juan de Goyeneche consiguió auparse como importante hombre de negocios en la corte madrileña y, desde allí, utilizar su creciente influencia para poner en contacto las posibilidades de abastecimiento naval de Navarra con las demandas de provisiones militares del estado. En este salto hacia delante de Goyeneche jugó un papel fundamental la posición de influencia política y económica alcanzada con la compra del cargo de la tesorería de la reina, que lo convirtió en un financiero destacado de la Casa Real ...": TORRES SÁNCHEZ, Rafael: "Los navarros en la provisión de víveres a la armada española durante el siglo XVIII", en Rafael Torres Sánchez (ed.), Volver a la hora navarra, Pamplona, EUNSA, 2010, pp. 213-262.

${ }^{65}$ Ya antes pagó sueldos de marina, como a Agustín Isidro Antón, maestro de embarcaciones del Real Sitio del Buen Retiro (Madrid), a través de su hermano mosén Patricio Antonio Antón, 146 libras y 8 sueldos: AHPA, Not. 1.323/25.1.1725. MONTOJO MONTOJO, Vicente: "La presencia de navarros en la Cofradía Marraja y la administración de hacienda de Cartagena de Levante en 1745-1773”, Huarte de San Juan, 25, 2018, pp. 9-26.
} 
que negociar, y que en Alicante se pretendió su aminoración. Se obtuvo además dinero de la Junta de Sanidad de Alicante ${ }^{66}$. Para su transferencia de una tesorería a otra se utilizaron letras de pago.

A Cartagena le compensó la capitalidad del departamento marítimo (1726) de sus castigos anteriores, pues implicó una afluencia de tropas y de población fabril y mercantil ${ }^{67}$. En lo que se refiere al movimiento portuario naval a finales de 1730 Patiño comunicó a Rubalcava que el navío Rubí, del mando de Diego de La Landa, llegaría a Cartagena y debía ser reparada cuanto antes y preparada para salir a navegar ${ }^{68}$.

\section{Guerra Anglo-española de 1727-1729 y expediciones de Parma y Orán (1731-1732)}

El comienzo del Departamento marítimo de Levante coincidió con la Guerra Angloespañola. Las principales acciones fueron un $2^{\circ}$ sitio español de Gibraltar (terrestre) y el bloqueo inglés de Portobelo ${ }^{69}$, fallidos. La guerra acabó por el Tratado de Sevilla (1729) en que España no ganó ningún territorio ${ }^{70}$, pero Felipe V e Isabel de Farnesio vieron reconocido el derecho de sucesión al ducado de Parma y Piacenza para uno de sus hijos.

Antonio Farnesio, duque de Parma, falleció en enero de $1731^{71}$ y el gobierno español organizó una expedición naval para la toma de posesión de los ducados de Parma y Plasencia por el infante Carlos de Borbón Farnesio, que recibió este derecho a través de su madre, sobrina de Antonio Farnesio.

Mientras hubo paz con Reino Unido (1729-1739) entró algún barco inglés en Cartagena. Miguel de Sada conde de Clavijo ${ }^{72}$ dirigió una escuadra que salió primero a Cádiz en junio de 1731 para unirse al resto. En la preparación en Cartagena, se aprovisionó de agua,

\footnotetext{
${ }^{66}$ GIMÉNEZ LÓPEZ, Enrique: Alicante en el siglo XVIII. Economía de una ciudad portuaria en el Antiguo Régimen, Valencia, Instució Alfons el Magnánim, 1981. ZABALA URIARTE, Aingeru: "El comercio internacional del puerto de Alicante en el siglo XVIII (1700-1780), en El comercio y la cultura del mar. Alicante, puerta del Mediterráneo, Valencia, Generalitat Valenciana, 2013, pp. 145-177.

67 "A partir de entonces, el poder militar del reino dependió por entero de la capitanía general de Valencia y Murcia, si bien el gobernador de Cartagena actuaba como su máximo representante en el territorio. La ciudad portuaria potenciaría su carácter militar con la construcción del arsenal y su designación por capital del departamento marítimo del Mediterráneo (1726)”: MUÑOZ RODRÍGUEZ, Julio D.: op.cit, p. 317. TORRES SÁNCHEZ, Rafael: Ciudad y población. El desarrollo demográfico de Cartagena en la Edad Moderna, Cartagena, Real Academia Alfonso X el Sabio, 1998.

${ }^{68}$ Archivo Naval de Cartagena (ANC), Reales Órdenes (RO), Patiño a Ruvalcaba 10.11.1730.

${ }^{69}$ MIJARES, Lucio: "Política exterior: la diplomacia”, en Historia General de España y América, t. 11-1, Madrid, Ediciones Rialp, 1989, $2^{\text {a }}$ ed., pp. 65-100, cfr. 70.

${ }^{70}$ FERNÁNDEZ DÍAZ, Roberto: Carlos III, Madrid, Arlanza, 2001, 46-7 y 63.

${ }^{71}$ FERNÁNDEZ DURO, Cesáreo: Armada española (desde la unión de los reinos de Castilla), Madrid, 1896, t. 6, pp. 198-200.

${ }^{72}$ GÓMEZ VIZCAINO, Juan Antonio: "El Departamento Marítimo de Cartagena bajo el mando de Miguel de Sada Antillón, Conde de Clavijo (1735-1741)”, Cartagena Histórica, 26, 2008, pp. 47-55.
} 
se reclutó marinería y tropas en los reinos de Valencia y Murcia para Italia, que se concentraron en Alicante para su traslado a Barcelona. Financiaron estos transportes los ingresos de la Aduana de Alicante, pues para los caudales de Indias ${ }^{73}$ hubo dificultad del poco tráfico entre Cádiz y Alicante. Desde Barcelona se transportó el ejército del infante Carlos de Borbón Farnesio a Liorna ${ }^{74}$. Para ello desde Cartagena se fletaron naves de transporte y se transportaron 300.000 raciones de víveres ${ }^{75}$.

Una parte de esta armada, la dirigida por Blas de Lezo, fue la que entró en el puerto de Génova y exigió la devolución de dos millones de pesos depositados por España en el Banco de San Jorge ${ }^{76}$, reclamados por haber sido entregados allí por los austracistas.

La conquista de Orán (1732) siguió a la expedición de Parma ${ }^{77}$. A principios de abril de 1732 la escuadra de Blas de Lezo, de 6 navíos, estuvo en Cartagena, necesitada de reparación. Patiño advirtió a Rubalcaba que aquella debía incorporarse a la expedición. La organización se llevó entonces en secreto, pero fue la que se destinó a la conquista de Orán ${ }^{78}$. La escuadra de Esteban de Mari regresó de Italia y tras numerosos preparativos a mitad de 1732 y con la de Blas de Lezo se dirigió a Orán y la conquistó.

El proveedor de víveres de la escuadra de galeras fue Pedro de Astrearena, navarro, quien tuvo en Cartagena como factores de víveres a Pedro Antonio Pereti y Andrés Chereguini, de origen genovés, antes administrador de la renta del tabaco ${ }^{79}$, quienes desempeñaron una gran actividad en estos años, pero la provisión de víveres fue proporcionada por un asentista (contratista), en esta época siempre un navarro, como Miguel Arizcum, del que Rubalcava mencionó su eficacia ${ }^{80}$. Los comerciantes y contadores genoveses de Cartagena aprovisionaron en concurrencia con otros franceses con los que negociaron, como en la prestación de fianzas ${ }^{81}$ o provisión de vino.

\footnotetext{
73 ZABALA URIARTE, Aingeru: "La Aduana de Alicante en el siglo XVIII", en El comercio y la cultura del mar. Alicante, puerta del Mediterráneo, Valencia, Generalitat Valenciana, 2013, pp. 183-199. SOLBES FERRI, Sergio: "El control del gasto de la Marina en las Secretarías de Estado y del Despacho. Los pagos de la Tesorería General en la primera mitad del siglo XVIII", en María Baudot Monroy (ed.), El Estado en guerra. Expediciones navales españolas en el siglo XVIII, Madrid, Ediciones Polifemo, 2014, pp. 147-193. MONTOJO MONTOJO, Vicente: "Sax: lugar de conflictividad en el comercio de Alicante en 1700-1746", El Castillo de Sax, 37, 2016, pp. 42-45.

${ }^{74}$ BAUDOT MONROY, María: "El regreso de Felipe V a Italia después de la Guerra de Sucesión. La expedición anfibia hispano-inglesa a la Toscana de 1731", Revista Universitaria de Historia Militar, 5/10, 2016, pp. 67-88.

${ }^{75}$ ANC, RO 7.2, 26.5, 6, 20.6, 18.7, 8, 15, 22, 29.8, 5, 12, 19, 26, 29.9, 3.10, 6 y 19.12.1731, 7, 8.4.1732.

${ }^{76}$ FERNÁNDEZ DURO, Cesáreo: op.cit., t. 6, pp. 187-8, 198-200.

77 ALBEROLA ROMÁ, Armando: "La expedición contra Orán del año 1732. El embarque de tropas en el puerto de Alicante", LQNT, patrimonio cultural de la ciudad de Alicante, 1, 1993, pp. 191-199.

${ }^{78}$ FE CANTO, Luís: "El desembarco en Orán en 1732. Aproximación analítica a una operación compleja", Revista Universitaria de Historia Militar, 5/10, 2016, pp. 89-110.

${ }^{79}$ AHPM, Not. Vicente, 6.189/57, 12.9.1729; 6.189/1, 10.1.1730.

80 ANC, RO 25.7, 13.10.1731, 12.8.1732, 24.1, 6, 18.6.1733.

${ }^{81}$ Lázaro Guiran, negociante francés de Alicante, fue fiador del capitán de galeota Sebastián Gallardo y D. José Martínez para patente de corso: AHPA, Not. 2218/343 y 344, 7 y 8.11.1719.
} 
Protagonista de esta coyuntura fue Carlos María Rizo, uno de los comerciantes genoveses importantes, natural de Voltri (Génova), que se instaló en Cartagena procedente de Alicante, como hicieron otros comerciantes, para sustituir a su hermano Ángel, que enfermó. Su hermano Mateo Rizo fue asimismo comerciante en Alicante. Carlos casó en Elche con una alicantina: Josefa María Cazorla (1713), hermana del doctor médico Cirilo Cazorla, vecino de Alicante, y fue socio del genovés de Alicante Antonio Pavía ${ }^{82}$, su primo, con el que entre otras cosas exportó sal alicantina ${ }^{83}$. Fue la suya una trayectoria que se observa en Antonio María Montanaro Leonardi, comerciante genovés de Cartagena, que casó con una mujer de Murcia, una Aguado, y que hubo de exiliarse en 1706, pero no su hermano Nicolás Montanaro Ansaldo.

Rizo como tantos otros se dedicó exportar barrilla, salicornia o sosa (producto derivado de quemar plantas halófilas o de tierras saladas, útil para tintes y vidrios ${ }^{84}$ y participó en el fletamento del navío La Princesa de Loarno, del capitán genovés Jerónimo Villani, de bandera inglesa, que participó en la recuperación de Orán, de modo que junto con Bartolomé Baso apoderó a Juan Bautista Fabián, comerciante de Alicante, para cobrar los fletes ${ }^{85}$.

Lo que sabemos de él y de otros comerciantes se basa fundamentalmente en las actas de los protocolos notariales de Alicante y Cartagena que sólo nos dan breve información más o menos aislada o contextualizada, salvo las de Vicente Navarro, escribano de la provisión de víveres de Alicante, Juan y Manuel Vicente Tauste, escribanos de Guerra y Rentas provinciales de Cartagena. De aquí que en sus protocolos figuren numerosas fianzas de arraigo y escrituras de otro tipo sobre provisiones navales.

Rizo fue además abastecedor de trigo (1724) y de nieve ${ }^{86}$ de Cartagena, durante muchos años, en que coincidió a veces con Julio Antonio Chereguini, Pedro Antonio Pereti, Miguel Lavarelo, Francisco Lavarelo, Miguel Turón, francés ${ }^{87}$, y Tomás Schirmer (1734), suizo. Hubo otro Pereti llamado Juan Bautista, comerciante primero en Cartagena, desde donde tuvo un pleito con otros de Alicante, y después en Granada ${ }^{88}$.

\footnotetext{
${ }^{82}$ Fueron por ejemplo destinatarios de dos letras de cambio de 65.000 y 45.833 reales de Madrid 1.2.1716 firmadas por Pablo Antonio Guilachi y Cía. a favor de Tomás Lambrichi y aceptadas por Pavía y Rizo el 16.3.1716: Archivo del Reino de Valencia (ARV), Escribanías de Cámara (EC), 1715, n.2.

83 AHPA, Hacienda, B n. 816: Entradas y salidas de salinas, 23.6.1711.

84 VELASCO HERNÁNDEZ, Francisco: "La Sosa-barrilla: una señal de identidad del Campo de Cartagena en los siglos XVI al XIX”, Revista Murciana de Antropología, 10, 2004, pp. 145-158. GIRÓN PASCUAL, Rafael María: "Cenizas, cristal y jabón. El comercio de la barrilla y sus derivados entre España e Italia a finales del siglo XVI (1560-1610)", eHumanista, 38, 2018, pp. 215-232.

85 AHPM, Not. J.M. Aguirre 5.521/121-2, 16.6.1733.

86 Archivo Municipal de Cartagena (AMC), Actas Capitulares (AC) 1730-32/180, 9.12.1730.

${ }^{87}$ Bearnés muy activo en Cartagena. Vendió una casa a Pedro Valentín, patrón de la galera Santa Teresa de las de España: AHPM, Not. Vicente, 6.189/88, 25.8.1728.

88 AHPM, Not. Madrid, 5817/495, 1733. Esteban Revel y Cía. contra Jacome Ferrari y Juan B. Pereti: ARV, EC, año 1723 , n. 65.
} 
El gobierno aumentó medidas de fomento del comercio, como las grandes compañías de Honduras (1714-1717) ${ }^{89}$ y Guipuzcoana $(1728)^{90}$, y la ampliación de la Junta de Comercio con Minas y Moneda (1730 ${ }^{91}$. La primera gran compañía pudo actuar mientras hubo paz con Francia y Reino Unido y la segunda al restablecerse. Algo parecido sucedió con la provisión de víveres por factoría, pero ésta tampoco pudo evitar tener que recurrir a los canales tradicionales de circulación de los víveres, que estaban en manos de comerciantes genoveses y franceses, en especial marselleses y bearneses, tanto de Alicante -o para la provisión de árboles de barcos ${ }^{92}$ - como de Cartagena.

Así, con Rizo trabajó Pedro Vergez, su albacea y de Josefa María Cazorla, bearnés como Turón, aunque en Cartagena hubo también comerciantes marselleses como Noel Bartolón, muy activo en estos años, a quien Claudio Brunet, de Marsella, quiso cobrar una deuda a través de Juan Valence y Juan Picher, negociantes franceses de Alicante ${ }^{93}$.

El vino era muy abundante y de calidad en Alicante ${ }^{94}$, pero menos en Cartagena donde una gran parte lo comerció Jacinto Ignacio Digueri, regidor de origen genovés ${ }^{95}$.

\section{Conclusiones}

Las expediciones militares y navales del reinado de Felipe V hasta 1732 dieron lugar a una logística en la que intervinieron comerciantes de los puertos del Levante español (Cartagena, Alicante), en cuyas actividades se comprueba a través de documentación notarial que colaboraron con comerciantes de Cádiz y Puerto de Santa María.

Esta constatación y comprobación se complementa con la advertida entre las autoridades de las proveedurías de armadas y fronteras de Cartagena, Málaga y Cádiz, que se mantuvieron a principios del XVIII, incluso entre las intendencias recién creadas en 1717

\footnotetext{
${ }^{89}$ RODRÍGUEZ GARCÍA, Margarita Eva: “Compañías privilegiadas de comercio con América y cambio político (1706-1765)", Estudios de Historia Económica, 45, 2005, pp. 1-81, v. 28.

90 GÁRATE OJANGUREN, Monserrat/BLANCO MOZOS, J.L.: "Financiación de las compañías privilegiadas de comercio en la España del siglo XVIII", en Rafael Torres Sánchez (ed.), Capitalismo mercantil en la España del siglo XVIII, Pamplona, Eunsa, 2000, pp. 173-209.

${ }^{11}$ CALDERÓN BERROCAL, Ma Carmen/ROMERO MACÍAS, Emilio Manuel: "Génesis y competencia de las Juntas de Comercio, Moneda y Minas", De re metalica, 14, 2010, pp. 61-69. En Cartagena se aplicó el nombramiento de marcador de pesos de oro y plata en Ignacio Ballester: AMC, AC 1730-32/185, 259 y 271, 20.12.1730, 1 y 26.6.1731. Los precios subían por las obras del departamento.

${ }_{92}$ Dos vecinos de Tobarra vendieron cáñamo para tal provisión: AHPA, Not. 1.323/13.9 y 31.10.1725.

93 AHPA, Not. Navarro, 1.325/5, 20.2.1637. Poder de Brunet: Marsella 22.2.1734, por lo que es anterior.

94 Jaime Llop Briosco compró a Pedro Choly, francés en Alicante, 15 toneles de vino a 27/1 el tinto y 23/1 el blanco: AHPA, Not. 2.218/344, 10.11.1719. MALDONADO, Leonor: "Negocios e integración social del comerciante marsellés Pedro Choly", Revista de Historia Moderna, 11, 1992, pp. 79-93.

${ }^{95}$ Hijo de Juan Antonio Digueri Imperial II, que se estableció en Cartagena en 1687-1688 procedente de Génova y recuperó el mayorazgo de su bisabuelo Vicente Imperial Jobardo (1638). Jacinto Ignacio arrendó repetidamente entre 1710 y 1746 el diezmo eclesiástico de uva y vino, y reclamó junto con Francisco Soler a Juan Ignacio González, comerciante de Cartagena, el valor de 1.527 arrobas de mosto.
} 
(Cádiz) y 1726 (Cartagena y Ferrol), en que la tendencia de los asentistas navarros a controlar la provisión de armadas no impidió la permanencia de los comerciantes de Cartagena de Levante y Alicante como abastecedores.

La creación del Departamento Marítimo de Levante (1726) y la necesidad de suministrar agua y otros productos a los navíos de la armada tuvo otra implicación, que fue la de desatascar la obra de la reforma de las conducciones de agua desde la huerta hasta la ciudad, en $1730^{96}$, necesaria para la asistencia de los navíos de guerra, lo que dio lugar a nuevas obras públicas, como la del dragado del puerto, la construcción de edificios y almacenes de comandancia general e intendencia y cuartel de guarnición ${ }^{97}$, siendo ocasión de un aumento de yeseras para la construcción ${ }^{98}$ y de población progresivo a partir de 1730 y en especial de artesanos.

96 AMC, AC 1730-1732/79-81, 23.6.1730. Se había dado antes: AMC, AC 1723-1726/140, 10.9.1723.

${ }^{97}$ Los veedores de albañilería presupuestaron el cuartel en 4.200 rls.: AMC, AC 1730-1732/155, 10.10.1730.

Antes se restauraron hornos bizcocheros: AMC, AC 1723-1726/646, 702, 21.5 y 16.11.1726.

${ }^{98}$ En poco tiempo fueron 3: AMC, AC 1730-32/327, 498, 501, 511, 13.10.1731, 16, 27.9 y 11.10.1732. 